\title{
NOTE
}

\section{Improved method of bacterial enumeration in sandy and deposit-feeder gut sediments using the fluorescent stain 4,6-diamidino-2-phenylindole (DAPI)}

\author{
Sabrina N. Hymel ${ }^{1}$, Craig J. Plante ${ }^{2, *}$ \\ ${ }^{1}$ Graduate Program in Marine Biology, University of Charleston, 205 Fort Johnson Road, Charleston, South Carolina 29412, USA \\ ${ }^{2}$ Department of Biology, Grice Marine Laboratory, University of Charleston, 205 Fort Johnson Road, Charleston, South Carolina 29412, USA
}

\begin{abstract}
A series of optimization experiments was carried out to improve visualization of DAPI-stained bacteria extracted from sandy sediments and midgut sediments of the deposit feeder Abarenicola pacifica. Treatments tested for the effects of fixative removal (prior to sonication) and removal of unbound DAPI (prior to filtration). Both quantitative (mean number of cells) and qualitative (cell fluorescence, background fluorescence, dispersion, cell counting rates) characteristics were examined. Removal of fixative and/or unbound stain did not significantly increase mean cell counts versus controls for sandy sediments, although variability (unbiased coefficient of variation) was reduced. Qualitative characteristics were not significantly improved by removing fixative, although visualization improved slightly and counting rates (cells $\mathrm{s}^{-1}$ ) increased with final removal of stain. In midgut sediments, removal of fixative and unbound stain resulted in increased cell counts as well as decreased variability. Significant improvements in contrast (i.e. increased cell fluorescence, decreased background fluorescence) were observed, as well as increased counting rate. These results indicate that both qualitative and quantitative aspects of direct counts may be improved by these methods for problematic sediments such as deposit-feeder gut and fecal samples or highly organic muds.
\end{abstract}

KEY WORDS: Bacteria - Enumeration - Sediment Epifluorescence - DAPI - Deposit-feeder

Enumeration of particle-attached bacteria is critical to understanding their ecology in marine sediments. Total direct counts under epifluorescence microscopy has emerged as the premier method to quantify both absolute and relative numbers of bacteria in sediments (Kepner \& Pratt 1994 and references therein, Epstein \& Rossel 1995, Epstein et al. 1997, and many others). In addition, direct counts of gut and fecal bacteria are

•E-mail: plantec@cofc.edu often made to determine the fate of bacterial production relative to deposit-feeding activities (e.g. Dobbs \& Guckert 1988, Duchêne et al. 1988, Plante et al. 1989, Grossmann \& Reichardt 1991, Plante \& Mayer 1994, Ward-Rainey et al. 1996, Lucas \& Bertru 1997). The application of an effective protocol for sample preparation and bacterial enumeration is necessary to provide consistent visualization, with each sediment type presenting unique challenges

The majority of bacteria in sediments are particleassociated (Dale 1974, DeFlaun \& Mayer 1983, Schallenberg et al. 1989), and numerous investigators have developed methods to dislodge bacteria from sediments. These have variously included shaking (Scheraga et al. 1979), homogenization (Dale 1974, Ellery \& Schleyer 1984, Bakken 1985), ultrasonication baths (Kepner \& Pratt 1994 and references therein) and ultrasonic probes (Yoon \& Rosson 1990, Velji \& Albright 1993, Epstein \& Rossel 1995). The dislodgement efficiency by these methods remains the subject of some debate. Epstein \& Rossel (1995) tested various dislodgement techniques and concluded that the use of an ultrasonic probe yielded the highest numbers of bacteria in sandy sediments.

Inherent in quantifying sedimentary versus watercolumn bacteria is the considerable amount of background debris which can obscure visualization. Many nonspecifically staining and autofluorescing components of sediments (e.g. free microalgal pigments, RNAs, etc.) are liberated during dislodgement protocols such as sonication (Schallenberg et al. 989). In addition, the fairly high concentrations of fluorochromes required to adequately stain sedimentary bacteria (Schallenberg et al. 1989, Kepner \& Pratt 1994) can result in nonspecific binding of excess stain to filter membranes. 
In our previous experiences with direct counts of sedimentary bacteria, we have encountered significant autofluorescence (primarily under blue excitation) nonspecific staining, and residual binding of the fluorochrome 4,6-diamidino-2-phenylindole (DAPI) to membranes. We have further observed that the digestive fluids associated with deposit-feeder (e.g. Arenicola marina, Abarenicola pacifica, Balanoglossus sp.) gut samples have contributed to high amounts of background fluorescence under UV excitation. All of these factors have resulted in a high degree of variability, even among replicate subsamples within pooled sediments.

In conjunction with current ecological studies in our laboratory, we have improved upon the methods of previous investigators (most recently, Epstein \& Rossel 1995 ) in the preparation of sediment samples for epifluorescence direct counts using DAPI. We provide here results of a series of optimization experiments involving sandy and deposit-feeder gut sediment samples.

Methods. Sediment sampling: $\operatorname{Six}, 10 \mathrm{~cm}^{3}$ cores of sandy sediment previously collected from Pawley's Island, South Carolina, USA, were taken from the surface to a depth of approximately $5 \mathrm{~cm}$ from a large holding tank. These were pooled, mixed thoroughly, and several $0.5 \mathrm{~cm}^{3}$ subsamples were immediately fixed in $1 \mathrm{ml}$ phosphate-buffered glutaraldehyde (GTA; see Kepner \& Pratt 1994) in sterile, $15 \mathrm{ml}$ polypropylene centrifuge tubes (final concentration $4 \%$ ). All samples were immediately refrigerated at $4^{\circ} \mathrm{C}$ until further processing, and stored no longer than 1 wk to minimize cell loss (see Turley \& Hughes 1992, Turley 1993).

Bacterial dislodgement: Bacteria were dislodged in 0.05 M Trizma (Sigma, St. Louis, Missouri, USA) buffer (pH 8.10). Starink et al. (1994) have reported enhanced blue-white fluorescence of DAPI-stained soil bacteria with the use of Trizma. Previous experiments (data not shown) indicated no numeric improvement between the use of Trizma buffer versus natural, filtered seawater. However, as we wished to eliminate the possibility of free RNAs and DNAs present in natural seawater (which might thus contribute to nonspecific staining), Trizma was chosen for all subsequent optimization experiments. Dislodgement was via sonic probe according to the methods of Epstein \& Rossel (1995), with the following modifications. A $3 \mathrm{~mm}$ microtip sonic probe was inserted into the buffer solution overlying the sediment sample in a $15 \mathrm{ml}$ centrifuge tube. Samples were sonicated over an ice bath for three $60 \mathrm{~s}$ bursts with a Branson Ultrasonifier 450 at an amplitude of $306 \mu \mathrm{m}$ and nominal power output of $65 \mathrm{~W}$ (setting 4 on the output control). Samples were allowed to cool at least $1 \mathrm{~min}$ between bursts. After the final sonication, the sediment was vortexed briefly and allowed to settle for $\sim 20 \mathrm{~s}$. A $5 \mathrm{ml}$ aliquot was then removed to a sterile, $50 \mathrm{ml}$ polypropylene centrifuge tube. An additional $5 \mathrm{ml}$ of buffer was then added to the sediment sample. The above washing/sampling procedure was repeated 8 times, yielding $40 \mathrm{ml}$ of pooled supernatant. All supernatants were immediately refrigerated at $4{ }^{\circ} \mathrm{C}$ until just prior to staining. The remaining sediment was filtered onto preweighed glass fiber filters and dried overnight at $60^{\circ} \mathrm{C}$ to obtain dry weights of sediment per subsample.

Each $40 \mathrm{ml}$ supernatant was vigorously shaken by hand and then lightly centrifuged $(508 \times g)$ for $10 \mathrm{~min}$ at $15^{\circ} \mathrm{C}$ to settle large particles. Two, $1 \mathrm{ml}$ aliquots were removed from each sample into sterile, $1.7 \mathrm{ml}$ polypropylene microcentrifuge tubes and incubated with $100 \mu \mathrm{l}$ of DAPI (100 ppm) in the dark for $15 \mathrm{~min}$. The contents of each tube were then vortexed briefly, filtered onto $25 \mathrm{~mm}$ black polycarbonate membrane filters $\left(0.2 \mu \mathrm{m}_{\text {i }}\right.$ Poretics) backed by glass fiber filters (Gelman, Type A/E), and rinsed with $5 \mathrm{ml}$ of filtered distilled water (FDW)

Experiments with removal of fixative: We first tested whether our GTA fixative contributed to variability in fluorescence. Prior to addition of sonication media, samples were centrifuged at $\sim 4000 \times \mathrm{g}$ for $15 \mathrm{~min}$ at $15^{\circ} \mathrm{C}$ to pellet contents. Without disturbing the sediment, $1 \mathrm{ml}$ of the GTA supernatant was pipetted off and retained for future counts. Samples were washed once in $1 \mathrm{ml}$ Trizma buffer and pelleted a second time, with the supernatants retained for future counts. Five $\mathrm{ml}$ of Trizma buffer, along with $50 \mu \mathrm{l}$ of $0.5 \%$ Triton $X-100$ (to enhance dislodgement and dispersion; see Epstein \& Rossel 1995) was then added, and sonication/washing was carried out as described above. Two, $1 \mathrm{mI}$ aliquots of the pooled supernatant, as well as those removed prior to sonication, were stained with DAPI and counted as previously described. Control treatments were sonicated and stained without initial removal of GTA.

Experiments with final removal of excess stain: We further tested whether background fluorescence associated with DAPI-stained bacteria was due to excess stain adhering to filters. Additional sandy sediment samples were fixed and sonicated as previously described, including initial removal of GTA. A 2 ml aliquot of pooled supernatant was removed to a sterile, $15 \mathrm{ml}$ centrifuge tube for staining. DAPI was added at a concentration of $100 \mu \mathrm{l} \mathrm{ml}^{-1}$, and the sample was incubated in the dark for $15 \mathrm{~min}$. Samples were then centrifuged at $\sim 4000 \times g$ for $15 \mathrm{~min}$ at $15^{\circ} \mathrm{C}$ to pellet contents. One $\mathrm{ml}$ of supernatant was then removed for counting, and the remainder decanted. Pellets were resuspended by vortexing in $2 \mathrm{ml}$ of FDW to which additional Triton $\mathrm{X}-100$ was added at a concentration of $1 \mu \mathrm{l} \mathrm{ml} \mathrm{m}^{-1}$ and sonicated in three $20 \mathrm{~s}$ bursts with the microprobe to improve pellet dispersion. A $1 \mathrm{ml}$ aliquot was then filtered onto each of 2 membrane filters and rinsed with 
$5 \mathrm{ml}$ FDW. Control treatments were prepared similarly, minus the final centrifugation procedure.

Gut samples: Six, large Abarenicola pacifica which had been feeding on sediments collected from Pawley's Island were dissected aseptically, and $\sim 0.1 \mathrm{~cm}^{3}$ of midgut sediment was removed from each, pooled and divided among sterile, pre-weighed $15 \mathrm{ml}$ centrifuge tubes $(n=6)$ and fixed overnight in $1 \mathrm{ml}$ of GTA. Samples were centrifuged at $\sim 4000 \times g$ for $15 \mathrm{~min}$ at $15^{\circ} \mathrm{C}$ to pellet contents. Approximately $1 \mathrm{ml}$ of the GTA supernatant was carefully pipetted off and saved for direct counts. The sediment sample was then suspended in $5 \mathrm{ml}$ of Trizma buffer, with Triton X-100 added $(50 \mu l)$ and sonicated as described above. However, due to the small volume of sediment, as well as the anticipated low numbers of bacteria ( $\mathrm{S}$. Hymel unpubl data), no further washing/diluting was performed. Two, $1 \mathrm{ml}$ aliquots of the supernatant were prepared for staining as for the sediment samples. After staining, as much of the supernatant as possible was pipetted off without disturbing the sediment. Tubes were then allowed to dry overnight at $60^{\circ} \mathrm{C}$, and re-weighed to obtain dry weights of gut sediment.

Counting: Filters were examined (by S. Hymel) under $1250 \times$ (Nikon Fluorite ${ }^{\mathbb{O}}$ oil immersion lens) with a Nikon Optiphot $-2^{\oplus}$ epifluorescence microscope, using a standard DAPI filter combination (365 nm excitation filter, $400 \mathrm{~nm}$ barrier filter). Twenty haphazardly selected fields (or 200 bacteria) were counted for each filter, and replicate filters were averaged after subtraction of blanks ( $1 \mathrm{ml}$ filtered distilled water stained with $100 \mu \mathrm{l}$ DAPI). For those experiments involving initial removal of fixative and/or final removal of stain, supernatants collected at each step were counted and added to final direct counts after subtraction of blanks. Bacterial numbers were calculated as the number of cells per gram dry weight of sediment (Ellery \& Schleyer 1984).

Assessment of qualitative characters: Four to six filters from experimental and control treatments were selected randomly over several days, coded and recounted anonymously in the following manner. The time to count each gridded field was measured via a stopwatch, averaged over 10 randomly selected fields per filter, and converted to cells counted per second (cells $\mathrm{s}^{-1}$ ). The same filter was then examined and ranked with respect to the following qualitative characters: (a) dispersion ( 1 = even, 2 = patchy); (b) cell fluorescence $(1=\text { bright, } 2=\text { moderate, } 3 \text { = weak })_{i}$ (c) background fluorescence ( $1=$ none, 2 = slight, $3=$ moderate, 4 = strong)

Analyses: Although data for each experiment were normally distributed (Shapiro-Wilk $W$-test), variances among various treatments were not homogeneous. Therefore, a modified version of the $t$-test for unequal variance was used (Sokal \& Rohlf 1981, p. 411-412).
All tests were 2-tailed. Unbiased coefficients of variation (CV) and standard errors (SCV) (Sokal \& Rohlf 1981, p. 150) were calculated in order to compare variability among treatments.

Logistic regression of ranked, qualitative characters was carried out, and the log-likelihood ratio (G-test for goodness of fit, Sokal \& Rohlf 1981, p. 695-696) was used to test for treatment effects.

Digital micrography: DAPI-stained bacteria were visualized on an Axioplan research microscope (Carl Zeiss Inc., Jena, Germany) equipped with a $100 \mathrm{~W}$ mercury light source and a $100 \times$ plan-neuluar na 1.3 objective. Images were captured with a Dage CCD100 integrating camera (Dage-MTI, MI, USA) and a Flashpoint 128 capture board (Integral Technologies, IN, USA). Image capture and processing were performed on a Dual Pentium Pro 200 Imaging workstation (Dell Computers, Texas, USA) using Image Pro Plus software (Media Cybernetics, Maryland, USA).

Results. Removal of fixative and excess stain: Removal of fixative prior to sonication in sandy sediment samples resulted in a slight, but not significant decrease in cell counts ( $t$-test, $p=0.34, d f=10)$ (Fig. 1), and a slight reduction in variability $(\mathrm{CV})$ with removal of fixative ( $C V=23.5 \%$ vs $25.8 \%$ ). No statistical difference was noted due to removal of excess stain prior to filtration ( $t$-test, $\mathrm{p}=0.90, \mathrm{df}=5$ ) (Fig. 2); however, there was a notable decrease in variability $(\mathrm{CV}=17.7 \%$ vs $26.3 \%$ ). Cell counts of supernatants collected during fixative removal or stain removal procedures generally accounted for less than $1 \%$ of total cell counts (data not shown); in many cases, these counts did not differ significantly from blanks.

Analysis of qualitative characteristics: Mean counting rates (cells $\mathrm{s}^{-1}$ ) did not differ significantly from controls with initial removal of fixative ( $t$-test, $p=0.72$, $\mathrm{df}=10$ ). However, final removal of stain resulted in a slight, but significant increase in cells s ${ }^{-1}$ versus controls ( $t$-test, $\mathrm{p}=0.03, \mathrm{df}=6)$. While neither treatment had a significant effect on dispersion, cell fluorescence

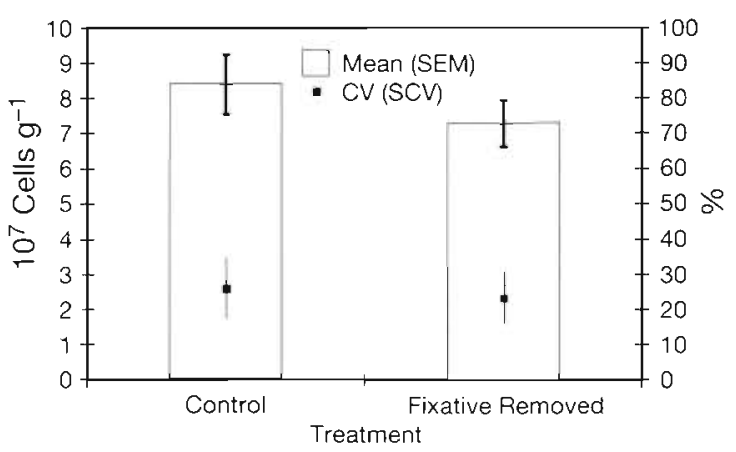

Fig. 1. Mean ( \pm SEM) cell counts and unbiased coefficients of variation (CV $\pm \mathrm{SCV}$ ) for sandy sediments; fixative removed prior to sonication/staining 


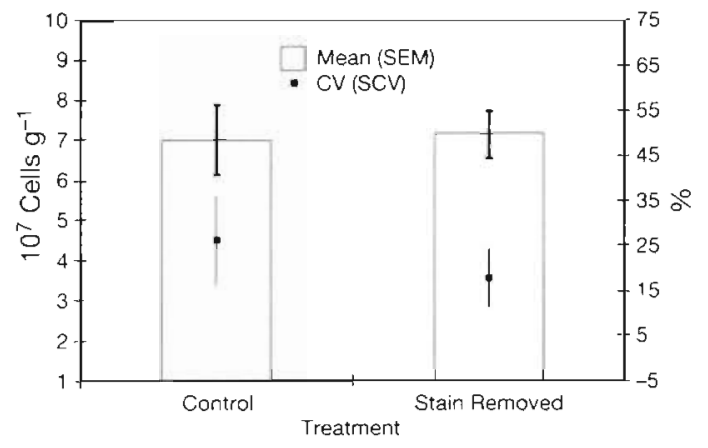

Fig. 2. Mean ( \pm SEM) cell counts and unbiased coefficients of variation $(\mathrm{CV} \pm \mathrm{SCV})$ for sandy sediments; fixative removed prior to sonication/staining, and stain removed prior to filtration

or background fluorescence (Table 1), visualization was improved slightly (Fig. 3A-D).

Gut samples: Midgut samples were tested solely for differences due to final removal of stain, as fixative was removed for both treatments and controls. This resulted in a $16 \%$ increase in cell counts, which was highly significant ( $t$-test, $p=0.01, \mathrm{df}=9$ ) (Fig. 4). Variability was also reduced after removal of excess stain (CV $=13.5 \%$ vs $24.1 \%$ ). Examination of slides for qualitative characteristics indicated a substantial improvment in overall visual quality (Fig, 3E, F) and resulted in a $10 \%$ increase in cells $\mathrm{s}^{-1}$ versus controls ( $t$-test, $\mathrm{p}=0.01$, $\mathrm{df}=9$ ). Analysis of ranked characters is summarized in Table 2. Cell fluorescence was improved ( $G$-test, $\mathrm{p}=0.05, \mathrm{df}=2$ ) and background fluorescence substantially reduced ( $G$-test, $p=0.001$, df $=2$ ) as compared with controls. Dispersion was statistically indistinguishable from controls.

Discussion. It has been shown recently that the use of an ultrasonic probe and staining with DAPI yields quantitative, not just relative, bacterial abundance estimates (Epstein et al. 1997). However, we have previously found that poor contrast between stained bacteria, detrital particles and background fluorescence frequently occurs and certainly casts doubt on both the precision and accuracy of direct counts obtained by these methods. Sediment samples collected from de-

Table 1. Analysis of qualitative characters for sandy sediments, fixative and/or stain removed vs controls. $(G=\log$ likelihood ratioj

\begin{tabular}{|lccccccc|}
\hline & \multicolumn{1}{c}{ Fixative removed } & \multicolumn{3}{c|}{ Stain removed } \\
& $G$ & $p$ & df & & $G$ & $p$ & df \\
\hline Dispersion & 0.45 & 0.5 & 1 & 0 & 1 & 1 \\
Cell fluorescence & 0.45 & 0.5 & 2 & 0.3 & 0.3 & 2 \\
Background fluorescence $^{4}$ & 4.59 & 0.2 & 2 & 0.68 & 0.7 & 2 \\
Counted cells s $^{-1}$ & 0.36 & 0.7 & 10 & 3.0 & 0.03 & 6 \\
\hline
\end{tabular}

posit-feeder guts pose additional problems, due to the presence of gut fluids and products of digestion. Thus in the preceding experiments, we sought to improve cellular fluorescence while also reducing background fluorescence in a protocol suited to both sediment and deposit-feeder gut samples

While removal of the GTA fixative did not result in significantly higher numbers of bacteria for sandy sediments, filtration onto membranes was somewhat facilitated. Qualitative characteristics improved moderately, though not significantly (Fig. 3A,B), indicating that residual GTA does not contribute either to reduced cell fluorescence or increased background fluorescence. Although separation of unbound DAPI prior to filtration did not significantly increase the total numbers of cells counted, improved visualization (Fig. 3C, D) was reflected in the increased counting rate observed (Table 1 ).

In midgut samples however, removal of the initial fixative/gut fluid mixture in samples substantially facilitated filtration onto membranes. Previously, we had found that filtration and rinsing times were up to 20 min for unwashed gut samples, and in some cases, clogged filters had to be discarded. While we are uncertain as to which components of gut fluids hinder filtration, we nonetheless recommend separation of fixative from samples prior to sonication.

A dramatic improvement in visualization was demonstrated for midgut sediments from which unbound DAPI was removed prior to filtration (Fig. 3E, F). Background fluorescence was virtually eliminated versus controls, and resulting counts increased significantly (Fig. 2). It may be that DAPI has a particular affinity for digestive fluids and/or products liberated during sonication, causing extensive non-specific staining. We observed similar problems of high background fluorescence and extensive non-specific staining for the green-fluorescent stain SYTO-13 (Molecular Probes, Eugene, Oregon, USA), although this stain has been used successfully for direct counts and flow cytometry (del Giorgio et al. 1996). A second possibility is that association with gut fluids and/or digestive products in some way interferes with nnsing unbound DAPI from

Table 2. Analysis of qualitative characters for gut sediments; fixative and stain removed vs controls. $(G=\log$ likelihood ratio)

\begin{tabular}{|lccc|}
\hline & & & Stain removed \\
& $G$ & $\mathrm{p}$ & $\mathrm{df}$ \\
\hline Dispersion & 1.1 & 0.3 & 1 \\
Cell fluorescence & 3.05 & 0.05 & 2 \\
Background fluorescence & 14.4 & 0.001 & 2 \\
Counted cells s $^{-1}$ & 3.2 & 0.01 & 9 \\
\hline
\end{tabular}




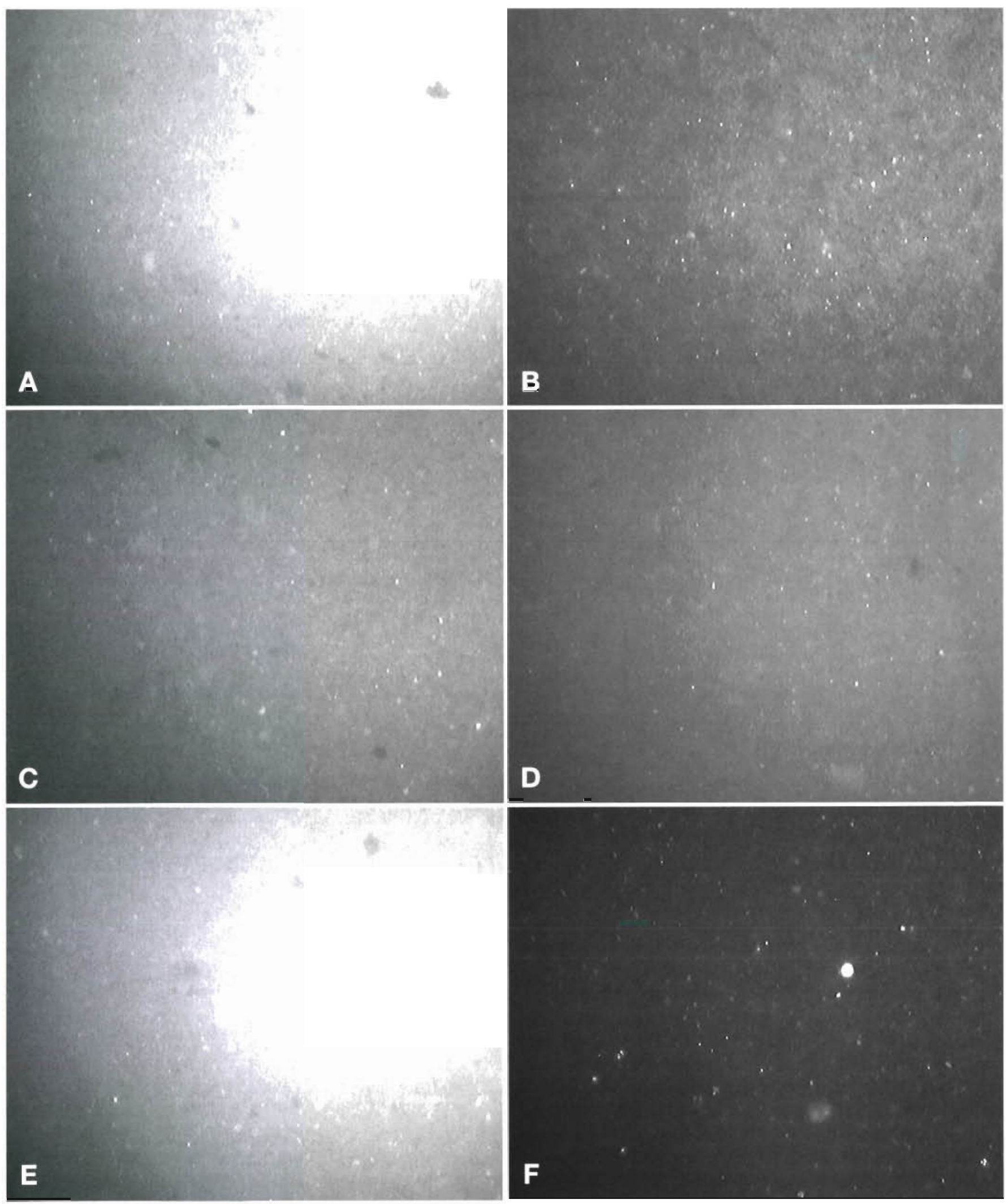

Fig. 3. Unretouched digital micrographs (1250x) of DAPI-stained sedimentary bacteria. (A) Control sample without removal of GTA fixative; (B) same sample, GTA fixative removed prior to sonication; (C) control sample with GTA fixative removed; (D) same sample with GTA fixative and excess stain removed; (E) midgut control sample, GTA fixative removed; (F) same sample with GTA fixative and excess stain removed 


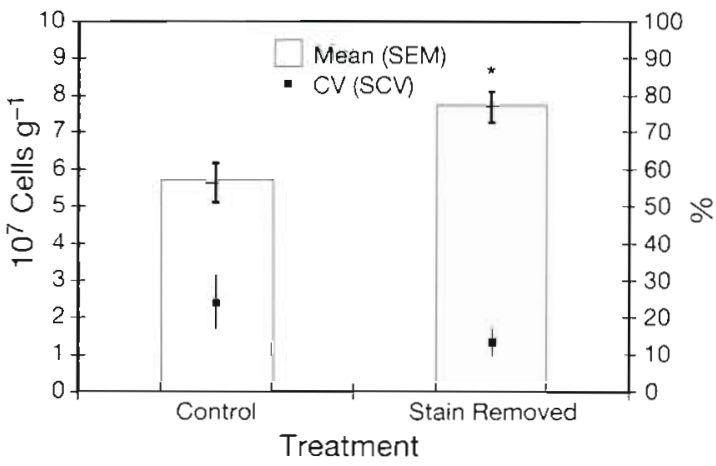

Fig. 4. Mean ( \pm SEM) cell counts and unbiased coefficients of variation (CV $\pm \mathrm{SCV}$ ) for midgut sediments extracted from the deposit-feeder Abarenicola pacifica. Treatment indicates fixative removed prior to sonication/staining, and stain removed prior to filtration. Significant differences indicated by * $p<$ 0.05 )

membranes. Further investigation into the chemical composition of deposit-feeder gut fluids will likely shed light on these processes.

Overall, our results indicate that the above modifications to the protocol of Epstein \& Rossel (1995) can overcome many of the handling and visualization problems unique to deposit-feeder gut samples, and thus facilitate counting by observers of all levels of experience. Visualization of DAPI-stained bacteria from freshly egested feces of the hemichordate worm Balanoglossus sp. (S. Wilde \& C. Plante unpubl.) has likewise been improved by our methods. And finally, our preliminary observations suggest that this protocol is favorable for enumerating bacteria from other problematic sediments such as highly organic muds.

Acknowledgements. This work was supported by National Science Foundation grant OCE 95-04505 made to C.J.P. We thank $\mathrm{D}$. Jones and 2 anonymous reviewers for constructive reviews of this manuscript. Assistance with digital micrographs was provided by J. Nicholson at the Medical University of South Carolina. This is contribution 148 of the Grice Marine Laboratory, University of Charleston, SC.

\section{LITERATURE CITED}

Bakken LR (1985) Separation and purification of bacteria from soil. Appl Environ Microbiol 49:1482-1487

Dale NG (1974) Bacteria in intertidal sediments: factors related to their distribution. Limnol Oceanogr 19:509-518

DeFlaun MF, Mayer LM (1983) Relationships between bacteria and grain surfaces in intertidal sediments. Limnol Oceanogr 28:873-881

del Giorgio PA, Brrd DF, Prairie YT, Planas D (1996) Flow cytometric determination of bacterial abundance in lake plankton with the green nucleic acid stain SYTO 13. Limnol Oceanogr 41(4):783-789

Dobbs FC, Guckert JB (1988) Microbial resources of the macrofaunal-deposit feeder Ptychodera bahamensis (Hemichordata: Enteropneusta). Mar Ecol Prog Ser 45:127-136

Editorial responsibility: John Dolan (Contributing Editor), Villefranche-Sur-Mer, France
Duchêne JC, Imbaud P, Delille D (1988) Associated bacterial microflora of a subantarctic polychaete worm Thelepus setosus. Arch Hydrobiol 112(2):221-231

Ellery WN, Schleyer MH (1984) Comparison of homogenization and ultrasonication as techniques in extracting attached sedimentary bacteria. Mar Ecol Prog Ser 15: $247-250$

Epstein SS, Alexander D, Cosman K, Dompé A, Gallagher $S_{\text {, }}$ Jarsobski J, Laning E, Martinez R, Panasik G, Peluso $C_{1}$ Runde R, Timmer E (1997) Enumeration of sandy sediment bacteria: are the counts quantitative or relative? Mar Ecol Prog Ser 151:11-16

Epstein SS, Rossel J (1995) Enumeration of sandy sediment bacteria: search for optimal protocol. Mar Ecol Prog Ser $117: 289-298$

Grossman S, Reichardt W (1991) Impact of Arenicola marina on bacteria in intertidal sediments. Mar Ecol Prog Ser 77: 85-93

Kepner RL Jr, Pratt JR (1994) Use of fluorochromes for direct enumeration of total bacteria in environmental samples: past and present. Microbiol Rev 58:603-615

Lucas F, Bertu $G$ (1997) Bacteriolysis in the gut of Nereis diversicolor (O.F. Muller) and the effect of diet. J Exp Mar Biol Ecol 215:235-245

Plante CJ, Jumars PA, Baross JA (1989) Rapid bacterial growth in the hindgut of a marine deposit feeder. Microb Ecol 18:29-44

Plante CJ, Mayer LM (1994) Distribution and efficiency of bacteriolysis in the gut of Arenicola marina and three additional deposit feeders. Mar Ecol Prog Ser 109:183-194

Schallenberg M, Kalff J, Rasmussen JB (1989) Solutions to problems in enumerating sediment bacteria by direct counts. Appl Environ Microbiol 55:1214-1219

Scheraga M, Meskill M, Litchfield CD (1979) Analysis of methods for the quantitative recovery of bacteria sorbed onto marine sediments. In: Litchfield CD, Seyfried PL (eds) Methodology of biomass determinations and microbial activities in sediments. ASTM STP 673. American Society for Testing and Materials, Philadelphia, p 21-39

Sokal R, Rohlf F (1981) Biometry. WH Freeman and Co, San Francisco

Starink M, Krylova IN, Bär-Gilissen J, Bak RPM, Cappengerg TE (1994) Rates of benthic protozoan grazing on free and attached sediment bacteria measured with fluorescently stained sediment. Appl Environ Microbiol 60:2259-2264

Turley CM (1993) Direct estimates of bacterial numbers in seawater samples without incurring cell loss due to sample storage. In: Kemp PF, Sherr BF, Sherr EB, Cole JJ (eds) Handbook of aquatic microbial methods. Lewis Publishers, Boca Raton, p 143-147

Turley CM, Hughes DJ (1992) Effects of storage on direct estimates of bacterial numbers of preserved seawater samples. Deep-Sea Res 39:375-394

Velji MI, Albright LJ (1993) Improved sample preparation for enumeration of agqreqated aquatic substrate bacteria. In: Kemp PF, Sherr BF, Sherr EB, Cole JJ (eds) Handbook of aquatic microbial methods. Lewis Publishers, Boca Raton, p 139-142

Ward-Rainey N, Rainey F, Stakebrandt E (1996) A study of the bacterial flora associated with Holothuria atra. J Exp Mar Biol Ecol 204:11-26

Yoon WB, Rosson RA (1990) Improved method of enumeration of attached bacteria for study of fluctuation in the abundance of attached and free-living bacteria in response to diel variation in seawater turbidity. Appl Environ Microbiol 56:595-600 